\title{
Correction to: Differentiation of COVID-19 conditions in planar chest radiographs using optimized convolutional neural networks
}

\section{Satyavratan Govindarajan ${ }^{1}$ (D) - Ramakrishnan Swaminathan ${ }^{1}$}

Published online: 25 March 2021

(C) Springer Science+Business Media, LLC, part of Springer Nature 2021

\section{Correction to: Applied Intelligence}

$$
\text { https://doi.org/10.1007/s10489-020-01941-8 }
$$

Figure 4 in the original article unfortunately contained an error. Two values are missing in the confusion matrix.

The original article has been corrected.

Publisher's note Springer Nature remains neutral with regard to jurisdictional claims in published maps and institutional affiliations.

The online version of the original article can be found at https://doi.org/ 10.1007/s10489-020-01941-8

Satyavratan Govindarajan s.vratan@gmail.com

1 Non-Invasive Imaging and Diagnostics Laboratory, Biomedical Engineering Group, Department of Applied Mechanics, Indian Institute of Technology Madras, Chennai, India 